Quim. Nova, Vol. 34, No. 9, 1544-1549, 2011

\title{
MOBILIDADE DE BÁRIO EM SOLO TRATADO COM SULFATO DE BÁRIO SOB CONDIÇÃo DE OXIDAÇÃo E REDUÇÃO
}

\author{
Marcio Osvaldo Lima Magalhães*, Nelson Moura Brasil do Amaral Sobrinho, Everaldo Zonta, Leilane da Silva Lima e \\ Filipe Soares Diniz de Paiva \\ Departamento de Solos, Instituto de Agronomia, Universidade Federal Rural do Rio de Janeiro, BR 465, km 7, 23890-000
}

Seropédica - RJ, Brasil

Recebido em 14/12/10; aceito em 19/4/11; publicado na web em 17/6/11

\begin{abstract}
BARIUM MOBILIT IN SOIL TREATED WITH BARIUM SULFATE UNDER CONDITIONS OF OXIDATION AND REDUCTION. In order to evaluate possible solubility of $\mathrm{BaSO}_{4}$ in soils under reducing conditions, column leaching assay was settled down, where the soil received three doses of $\mathrm{BaSO}_{4}\left(100,300\right.$ and $\left.3000 \mathrm{mg} \mathrm{kg}^{-1}\right)$ at two humidities. After reaching an Eh of $-200 \mathrm{mV}$ rainfall of $200 \mathrm{~mm}$ per day ${ }^{-1}$ was simulated. The condition of reduction led to the increased levels of barium in the fractions of higher lability and the highest levels of barium in the leachate extract, which were above the potability standards. Only $0.05 \%$ of barium in the column that received the highest dose was removed by leaching.
\end{abstract}

Keywords: soil contamination; redox potential; Ba.

\section{INTRODUÇÃO}

O bário pertence ao grupo dos metais alcalinos terrosos e é encontrado principalmente no mineral baritina $\left(\mathrm{BaSO}_{4}\right)$, sendo pouco observado na forma de íon livre na natureza devido a sua elevada reatividade. Esse metal também está presente em pequenas quantidades nas rochas ígneas, tais como feldspatos e micas, podendo ser encontrado como componente natural de combustíveis fósseis. ${ }^{1} \mathrm{E}$ amplamente utilizado na indústria petrolífera como componente de fluidos de perfuração devido a sua elevada densidade $\left(4,2 \mathrm{~g} \mathrm{~cm}^{-3}\right)$ na forma de baritina. ${ }^{2} \mathrm{O}$ bário contido na baritina é relativamente imóvel e pouco biodisponível, devido à baixa solubilidade em água $(2,47$ $\mathrm{mg} \mathrm{L}^{-1}$ a $25^{\circ} \mathrm{C}$ ), entretanto, na forma $\mathrm{Ba}^{+2}$ é tóxico. ${ }^{3}$

Durante a perfuração de poços para a prospecção e produção de petróleo, o fluido é misturado à rocha moída, liberando substâncias que estavam em sua composição ${ }^{4} \mathrm{e}$, consequentemente, tornando-se uma das principais influências nos teores de bário e outras substâncias nos resíduos de poços de perfuração de petróleo. ${ }^{5}$

Particularmente, quando os solos são alagados, o metabolismo microbiano e o equilíbrio dos elementos e compostos são alterados, desencadeando uma série de transformações, principalmente, químicas e microbiológicas que levam a um novo estado de equilíbrio desse ambiente, com características bem distintas das encontradas inicialmente. ${ }^{6}$ Esse novo ambiente químico é de grande importância ecológica, pois a mudança no estado de oxirredução modifica a biodisponibilidade e a mobilidade dos diferentes elementos presentes no solo. Nesse ambiente, os micro-organismos anaeróbicos, que utilizam os compostos oxidados do solo como receptores de elétrons no seu metabolismo, apresentam a seguinte sequência de transferência de elétrons: o primeiro receptor é o nitrato, depois os óxidos de $\mathrm{Mn}$ (IV), óxidos de Fe (III), seguido pelo sulfato e por último o carbono, sendo reduzidos, respectivamente, a $\mathrm{N}_{2}, \mathrm{Mn}^{+2}, \mathrm{Fe}^{+2}$, sulfeto e metano. ${ }^{7}$ Em ambientes com severa redução a solubilidade do sulfato de bário pode ser alterada. ${ }^{8}$

\footnotetext{
*e-mail: marciomagalhaes@gmail.com
}

Apesar da baixa solubilidade do sulfato de bário em solos, ${ }^{9}$ alguns estudos indicam que a baritina $\left(\mathrm{BaSO}_{4}\right)$ poderá funcionar como fonte de sulfato na respiração de bactérias anaeróbicas, ${ }^{8,10}$ podendo promover o aumento da solubilidade e liberação de $\mathrm{Ba}^{+2}$ no ambiente, potencializando a transferência desse elemento para a cadeia alimentar e a contaminação das águas subsuperficiais. ${ }^{11,12}$ Em estudo realizado por Nogueira et al. ${ }^{13}$ sobre o efeito de aplicações sucessivas de lodo de esgoto nos teores de bário no solo e plantas, verificaram que houve aumento na absorção do elemento pelas plantas, porém não em níveis que possam ser considerados tóxicos.

A disposição de resíduos oriundos de poços de perfuração de petróleo em áreas sujeitas a alagamento poderá potencializar os riscos de contaminação do ambiente com esse elemento. ${ }^{4}$

Este trabalho teve como objetivo avaliar, através de ensaios com colunas de lixiviação de solo, a mobilidade do bário em solo sob condição de redução.

\section{PARTE EXPERIMENTAL}

O solo utilizado foi coletado na profundidade de $0-20 \mathrm{~cm}$, no município de Pinheiral, situado na região do Médio Vale do Paraíba Fluminense, no sul do Estado do Rio de Janeiro.

As características físicas e químicas das amostras de terra foram determinadas conforme EMBRAPA ${ }^{14}$ e são apresentadas na Tabela 1. Após a coleta, o solo utilizado no experimento foi seco ao ar, destorroado, peneirado em tamis de malha de $4,5 \mathrm{~mm}$ e homogeneizado.

Foi realizada a abertura em triplicata, de uma subamostra do solo em estudo, com água régia ${ }^{15}$ para quantificar a concentração pseudototal de bário. Para validação da determinação do teor pseudototal de bário no solo utilizou-se material certificado de referência (NIST SRM 2709a, San Joaquin Soil - que apresenta teor de bário de 979 $\pm 28 \mathrm{mg} \mathrm{kg}^{-1}$ ), obtendo-se uma recuperação de $95 \%$, estando dentro dos intervalos admitidos pelo NIST como normais para a amostra SRM 2709a.

As colunas de lixiviação foram preparadas utilizando-se tubos de PVC, com $60 \mathrm{~cm}$ de altura e $100 \mathrm{~mm}$ de diâmetro, onde foram 
Tabela 1. Características químicas e teor de argila do solo utilizado

\begin{tabular}{|c|c|c|c|c|c|c|c|c|c|c|c|c|c|c|}
\hline $\mathrm{Na}$ & $\mathrm{Ca}$ & $\mathrm{Mg}$ & $\begin{array}{c}\mathrm{K} \\
-\mathrm{cm}\end{array}$ & $\begin{array}{l}\mathrm{H}+\mathrm{Al} \\
\mathrm{dm}^{-3}\end{array}$ & $\mathrm{Al}$ & $\mathrm{S}$ & $\mathrm{T}$ & $\mathrm{V}$ & $\begin{array}{l}\mathrm{m}^{1} \\
\%-\end{array}$ & $n^{2}$ & $\mathrm{pH}$ & $\mathrm{C}_{\text {org }}$ & $\begin{array}{l}\text { Argila } \\
-1 \\
\end{array}$ & $\begin{array}{c}\mathrm{Ba}^{3} \\
\mathrm{mg} \mathrm{kg}^{-1}\end{array}$ \\
\hline 0,03 & 3,2 & 2,0 & 0,01 & 4,5 & 0,2 & 5,2 & 9,72 & 54 & 3,9 & 0 & 5,8 & 10,7 & 596 & $223 \pm 4,3$ \\
\hline
\end{tabular}

${ }^{1}$ Saturação por Al; ${ }^{2}$ saturação por Na; ${ }^{3}$ média referente a 8 repetições obtidas por extração com água-régia (ISO 11466 ) e quantificadas por ICP-OES.

encaixados na extremidade funis para facilitar a coleta do extrato lixiviado. Para evitar o escoamento preferencial pelas paredes dos tubos colocou-se parafina inerte no limite entre a parede da coluna e o solo.

Foram incorporadas doses de bário baseadas nos valores orientadores propostos pela resolução 420 CONAMA $^{16}$ utilizando-se como fonte o sulfato de bário $\left(\mathrm{BaSO}_{4}\right)$. Os tratamentos foram: testemunha - substrato (solo) sem aplicação de bário; dose de $100 \mathrm{mg} \mathrm{kg}^{-1}$ - valor intermediário entre os valores de referência de qualidade e o valor de prevenção; dose de $300 \mathrm{mg} \mathrm{kg}^{-1}$ - valor de investigação e dose de $3000 \mathrm{mg} \mathrm{kg}^{-1}$ - dez vezes o valor de investigação.

As colunas receberam o volume de $5 \mathrm{dm}^{3}$ de solo com as respectivas doses, misturado manualmente em sacos plásticos. Os solos foram mantidos sob duas condições de umidade: $70 \%$ da capacidade de campo e saturação. Para garantir a saturação e a condição de redução, manteve-se uma lâmina de água de $7 \mathrm{~cm}$ na superfície do solo da coluna. Todas as unidades experimentais foram mantidas sob condição de drenagem impedida e cobertas com papel alumínio para evitar a perda de água por evaporação. Foram preparadas 32 unidades experimentais em delineamento experimental fatorial $(4 \mathrm{x}$ 2) composto por testemunha, 3 doses de $\mathrm{BaSO}_{4}, 2$ níveis de umidade e com 4 repetições.

Durante o período de incubação, foram determinados os valores de pH e Eh, 2 h após a inundação, aos 2, 4 e 6 dias. Após a primeira semana de incubação a determinação passou a ser realizada semanalmente, até a estabilização do potencial redox necessário para que ocorresse a redução do $\mathrm{SO}_{4}{ }^{2-}$, i.e, valores na faixa de -150 a -200 mV de Eh, para o solo saturado. Ao atingir os valores de potencial redox desejado (-150 a $-200 \mathrm{mV})$, aguardou-se 30 dias para que as reações de redução viessem a ocorrer e liberar o $\mathrm{Ba}^{2+}$ para a solução e, posteriormente, iniciou-se o teste de lixiviação. $\mathrm{O}$ ensaio de lixiviação consistiu na aplicação de uma lâmina de água equivalente à simulação de uma chuva de $200 \mathrm{~mm} \mathrm{dia}^{-1}$, correspondendo à aplicação total de $1,6 \mathrm{dm}^{3}$ de água para a seção da coluna, em uma única vez. $\mathrm{O}$ volume total adicionado foi dividido em volumes de $200 \mathrm{~mL}$, que corresponde a 1/8 do volume de poro do solo estudado.

Para as colunas que se apresentavam saturadas, com a presença de lâmina, foi adicionada água, retirando-se a tampa na saída do funil e coletado, simultaneamente, o volume de $200 \mathrm{~mL}$ em garrafas plásticas descontaminadas. Para as colunas que se apresentavam a $70 \%$ da capacidade de campo, foi adicionada água até a saturação e só após, colocado o volume correspondente à maior chuva, também sendo coletado, simultaneamente, na saída do funil o volume de $200 \mathrm{~mL}$. Ao final do ensaio o volume total de água coletado em cada unidade experimental foi de 1,6 $\mathrm{dm}^{3}$, divididos em 8 garrafas plásticas com $200 \mathrm{~mL}$ cada.

Os extratos coletados no ensaio com colunas foram analisados quanto aos teores de bário e comparados com os valores orientadores para potabilidade segundo a resolução 420 do CONAMA. ${ }^{16}$ Os teores de bário foram quantificados em aparelho de espectrômetro de emissão por plasma (ICP-OES), marca Perkin Elmer, modelo Optima 3000, com LD ( $\left.\mathrm{mg} \mathrm{kg}^{-1}\right)$ de 0,036 e LQ $\left(\mathrm{mg} \mathrm{kg}^{-1}\right)$ de 0,36 para bário nos extratos da digestão de solo e nos efluentes coletados nas colunas de solo. O limite de detecção (LD) do método foi calculado pela média dos valores dos brancos mais três vezes o desvio padrão do branco de todas as análises (10 repetições). Após a quantificação das con- centrações do elemento em estudo, foi calculado o total removido e o percentual em relação às quantidades presentes em cada tratamento.

O fracionamento geoquímico do bário foi realizado antes do ensaio de lixiviação (após o período de incubação) e após o ensaio de lixiviação, em todas as unidades experimentais e com 4 repetições. O método utilizado foi o recomendado pelo European Communities Bureau of Reference (BCR), empregado por Sahuquillo et al. ${ }^{17}$ As frações geoquímicas foram definidas como: F1: extraído com solução de ácido acético $0,11 \mathrm{~mol} \mathrm{~L}^{-1}$ (Fração ácido solúvel); F2: extraído com solução de cloridrato hidroxilamina $0,1 \mathrm{~mol} \mathrm{~L}^{-1}$ (fração ligada aos óxidos de Fe e Mn); F3: extraído com as soluções de peróxido de hidrogênio $8,8 \mathrm{~mol} \mathrm{~L}^{-1}$ e acetato de amônio $1,0 \mathrm{~mol} \mathrm{~L}^{-1}$ (fração ligada à matéria orgânica) e F4: extraído com água régia $-\Sigma$ das frações anteriores (fração residual).

Foram efetuadas as seguintes análises estatísticas: Teste de Lilliefors para verificação da normalidade, Teste de Cochran e Bartlett para verificar a homogeneidade das variâncias, análise de variância, teste de médias Tukey ao nível de 5\% de probabilidade e análise de regressão. Todas as análises estatísticas foram feitas por meio do Programa Estatístico SAEG Versão 9.0 (Fundação Arthur Bernardes na UFV, Viçosa - MG).

\section{RESULTADOS E DISCUSSÃO}

A variação do potencial redox (Eh) nos diferentes níveis de umidade em função do tempo de alagamento é apresentada na Figura 1A. Observa-se uma redução brusca nos valores de Eh no solo saturado após a primeira semana, atingindo valores negativos na terceira semana. O valor de $-200 \mathrm{mV}$ só foi alcançado na $11^{\circ}$ semana. Os valores de Eh nas colunas de solo com o nível de umidade a $70 \%$ da capacidade de campo variaram na faixa de $+400 \mathrm{a}+450 \mathrm{mV}$ e estão dentro da faixa considerada para solo oxidado. ${ }^{18}$

Nas colunas de solo na condição de saturação, verifica-se que com o tempo de alagamento ocorreu uma queda e posterior estabilização nos valores de Eh a valores abaixo de -200 mV, sendo considerada uma condição de severa redução. De acordo com a literatura, ${ }^{6,19,20}$ nesse valor de Eh já poderá ocorrer a redução do sulfato a sulfeto pelas bactérias (BRS) presentes no solo. $\mathrm{O}$ receptor de elétrons, que antes era o $\mathrm{O}_{2}$, passa a ser outros componentes inorgânicos que serão reduzidos. Essa condição altera o equilíbrio dos elementos e dos compostos do solo, resultando em importantes alterações químicas, físicas, biológicas e mineralógicas, sendo a mudança mais significativa o decréscimo no potencial redox. ${ }^{21}$

Observa-se no início do alagamento valores de Eh de $+350 \mathrm{mV}$ e de $\mathrm{pH}$ abaixo de 6,0. Com o decorrer do tempo de saturação ocorre redução nos valores de Eh e aumento dos valores de $\mathrm{pH}$ (Figura 1B). Esse aumento no $\mathrm{pH}$ é característico de solos sob condição de alagamento, devido ao consumo de prótons e como resultado espera-se mudança no $\mathrm{pH} .{ }^{6,19-21}$ Segundo Camargo et al., ${ }^{18}$ os índices Eh e pH refletem as atividades de prótons e elétrons no solo, uma vez que o excesso de um proporciona o déficit do outro.

Verificou-se nas últimas semanas de alagamento a estabilização dos valores de potencial redox em aproximadamente $-200 \mathrm{mV}$ e valores de $\mathrm{pH}$ próximos à neutralidade $(7,5)$. Segundo Camargo et $a l .,{ }^{22} \mathrm{o}$ aumento do $\mathrm{pH}$ após a submergência, depende não somente da relação do íon $\mathrm{OH}^{-}$e do consumo do íon $\mathrm{H}^{+}$, mas também da relação de 

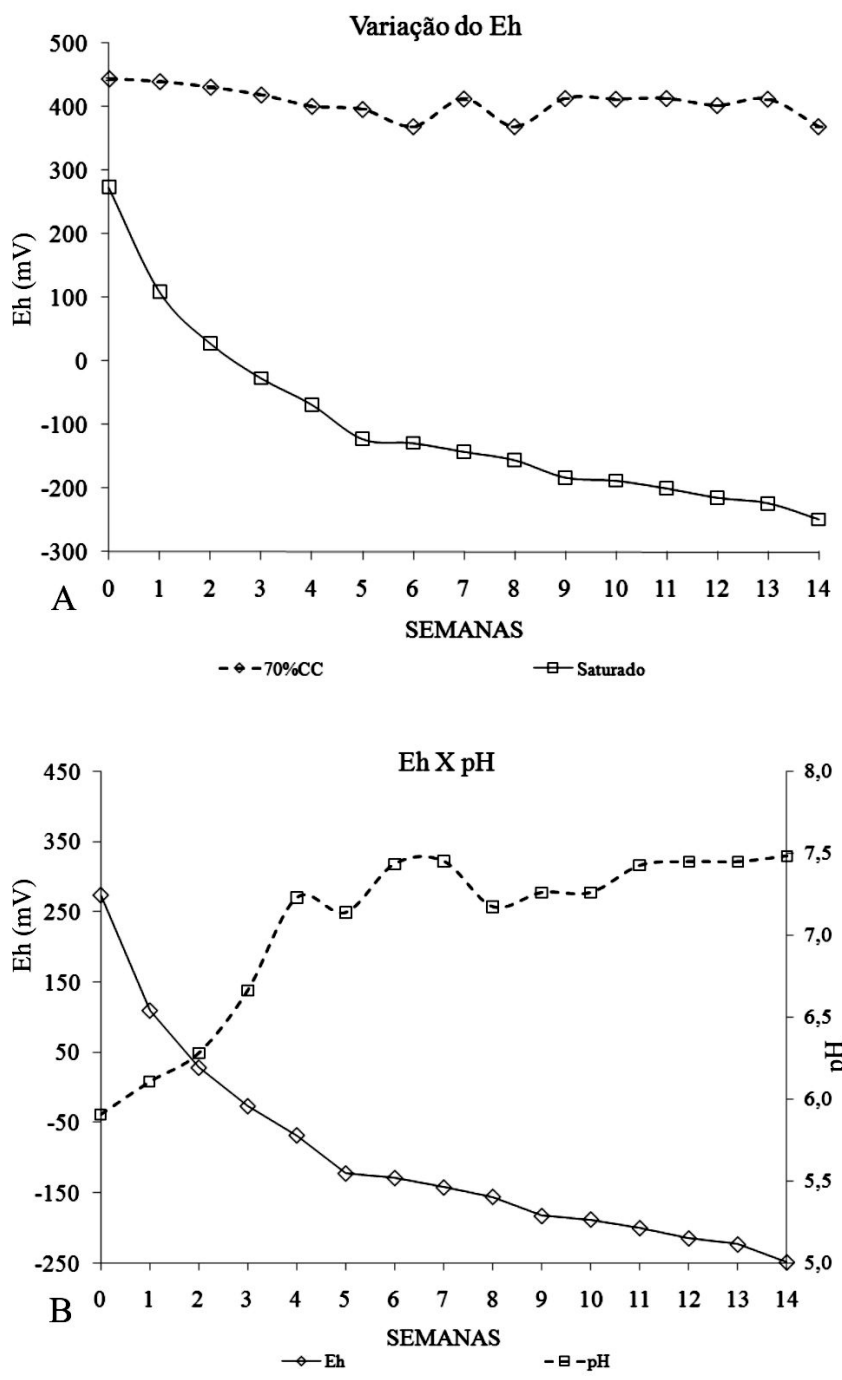

Figura 1. Valores de potencial de oxirredução (Eh) para dois teores de umidade e relação entre Eh e $\mathrm{pH}$ da solução em função das semanas após o alagamento

íons $\mathrm{H}^{+}$consumidos/elétrons consumidos. A mudança de $\mathrm{pH}$ depende necessariamente de duas condições, um processo de redução bem desenvolvido e a presença suficiente de ferro reduzido..$^{22,23}$

Quando se avaliam as médias de bário nas diferentes frações geoquímicas obtidas pelo método BCR (Tabela 2), observa-se comportamento diferenciado das frações em função das umidades.

Ao avaliar o fracionamento geoquímico em função do teor de umidade do solo, na testemunha, verifica-se que na fração ácido solúvel (F1) há um aumento significativo dos teores de bário nas condições em que o solo apresenta redução severa $(-200 \mathrm{mV})$, principalmente na maior dose. Essa informação pode ser demonstrada pelas variações percentuais de cada fração geoquímica em função da umidade do solo. A testemunha apresentou pouca diferença entre as umidades, de $17,9 \mathrm{mg} \mathrm{kg}^{-1}(0,6 \%)$ a $70 \%$ da capacidade de campo para $28,5 \mathrm{mg} \mathrm{kg}^{-1}$ (1\%) na condição de saturação. Na menor dose o teor de bário na fração F1, na condição oxidada, era de $99,9 \mathrm{mg} \mathrm{kg}^{-1}$ (3\% do total) elevando-se para $124,9 \mathrm{mg} \mathrm{kg}^{-1}$ (4\% do total) na condição de redução. Entretanto, na dose de $300 \mathrm{mg} \mathrm{kg}^{-1}$ o solo sob condição de oxidação apresentou teor de bário de $178,2 \mathrm{mg} \mathrm{kg}^{-1}$ (6\% do total) e na de redução de $265,6 \mathrm{mg} \mathrm{kg}^{-1}$ (9\% do total). Na maior dose, os valores foram de $220,7 \mathrm{mg} \mathrm{kg}^{-1}$ ( $7 \%$ do total) no solo oxidado e de $355,9 \mathrm{mg} \mathrm{kg}^{-1}$ (12\% do total) no solo saturado. Observa-se que ao aumentar a dose há maior diferença entre as umidades, sendo para a maior dose um aumento de $7 \%$ no solo a $70 \%$ da capacidade de campo para $12 \%$ na condição de saturação. Essa fração inclui o bário em solução, adsorvido eletrostaticamente na superfície dos coloides do solo (trocáveis) e os precipitados na forma de carbonatos. ${ }^{24,25}$

Esse aumento da fração F1 no solo saturado foi acompanhado da redução das concentrações de bário na fração associada aos óxidos. Rodriguez et $a l .{ }^{26}$ ressaltam que a associação dos metais com os óxidos não garante a imobilização na superfície, pois nessa fração esses elementos ainda são instáveis e podem ser liberados pela redução dos óxidos e, consequentemente, causarem impacto negativo sobre o solo e a biota. ${ }^{27}$

Entretanto, não foi observada diferença significativa nas concentrações desse elemento na fração ligada a matéria orgânica (F3). Esses resultados demonstram a baixa afinidade do bário pela matéria orgânica, visto que, essa complexação é considerada limitada. ${ }^{28}$ Smeda e Zyrnicki, ${ }^{29}$ também utilizando fracionamento geoquímico, verificaram que apenas $1 \%$ do bário se apresentava na fração ligada à matéria orgânica. Isso ocorre, provavelmente, devido à baixa afinidade do bário pelos sítios de ligação dos compostos orgânicos. ${ }^{30}$

$\mathrm{Na}$ fração residual (F4), diferentemente da testemunha, a condição de redução provocou alterações nos teores de bário extraído nessa fração. Verifica-se uma tendência contrária à observada na F1, ou seja, houve redução significativa dos valores de bário nas colunas com solo saturado. Observa-se que a redução na menor dose foi de $191,4 \mathrm{mg} \mathrm{kg}^{-1}$ (64\% do total) para $167,9 \mathrm{mg} \mathrm{kg}^{-1}$ (56\% do total), na dose de $300 \mathrm{mg} \mathrm{kg}^{-1}$ de $240,0 \mathrm{mg} \mathrm{kg}^{-1}$

Tabela 2. Distribuição do bário $\left(\mathrm{mg} \mathrm{kg}^{-1}\right)$ nas diferentes frações geoquímicas em função da testemunha, doses e teor de umidade

\begin{tabular}{|c|c|c|c|c|c|c|}
\hline & Umidade & Testemunha & Dose de 100 & $\begin{array}{l}\text { Dose de } 300 \\
-\mathrm{mg} \mathrm{kg}^{-1}\end{array}$ & Dose de 3000 & $\mathrm{CV}$ \\
\hline \multirow[t]{2}{*}{$\mathrm{F} 1$} & 70\% C.C & $17,6 \mathrm{Db}$ & $99,9 \mathrm{Cb}$ & $178,2 \mathrm{Bb}$ & $220,7 \mathrm{Ab}$ & 8,81 \\
\hline & Saturado & $28,5 \mathrm{Da}$ & $124,9 \mathrm{Ca}$ & $265,6 \mathrm{Ba}$ & $355,9 \mathrm{Aa}$ & \\
\hline \multirow[t]{2}{*}{$\mathrm{F} 2$} & 70\% C.C & $11,7 \mathrm{Ca}$ & $25,6 \mathrm{Ca}$ & $144,3 \mathrm{Ba}$ & $284,8 \mathrm{Aa}$ & 14,87 \\
\hline & Saturado & $7,4 \mathrm{Cb}$ & $22,5 \mathrm{Ca}$ & $116,6 \mathrm{Bb}$ & $324,1 \mathrm{Aa}$ & \\
\hline \multirow[t]{2}{*}{ F3 } & $70 \%$ C.C & $4,2 \mathrm{Ca}$ & $6,2 \mathrm{Ba}$ & $10,5 \mathrm{Ba}$ & $396,7 \mathrm{Aa}$ & 15,40 \\
\hline & Saturado & $3,6 \mathrm{Ba}$ & 7,8 Ba & $18,4 \mathrm{Ba}$ & $365,3 \mathrm{Aa}$ & \\
\hline \multirow[t]{2}{*}{$\mathrm{F} 4$} & 70\% C.C & $189,5 \mathrm{Ba}$ & $191,4 \mathrm{Ba}$ & $240,0 \mathrm{Ba}$ & $2320,7 \mathrm{Aa}$ & 4,04 \\
\hline & Saturado & $183,5 \mathrm{Ba}$ & $167,9 \mathrm{Bb}$ & $172,4 \mathrm{Bb}$ & $2177,7 \mathrm{Ab}$ & \\
\hline
\end{tabular}

F1 - Fração ácido solúvel; F2 - Fração ligada a óxido de ferro e manganês; F3 - Fração ligada à matéria orgânica e a sulfetos; F4 - residual. Letras seguidas de mesma letra (maiúsculas na linha e minúsculas na coluna) não diferem significativamente pelo teste de Tukey a $5 \%$. Testemunha - sem aplicação de sulfato de bário. 
(48\% do total) para $172,4 \mathrm{mg} \mathrm{kg}^{-1}$ (34\% do total) e na maior dose a redução foi de $2320,7 \mathrm{mg} \mathrm{kg}^{-1}$ (72\% do total) para $2177,7 \mathrm{mg} \mathrm{kg}^{-1}$ (68\% do total). Em estudo realizado por Smeda e Zyrnicki, ${ }^{29}$ também foram verificadas concentrações mais elevadas de bário nessa fração.

Os resultados obtidos do fracionamento geoquímico demonstram, de forma clara, que a condição de redução proporcionou a redução dos teores de bário das frações mais estáveis (F2 e F4) e aumento na fração de maior labilidade (F1), aumentando o risco de contaminação ambiental. ${ }^{10,31,32}$

Não há diferença significativa entre os teores de bário lixiviados nos diferentes pontos de coleta, ou seja, cada volume coletado dentro de cada dose (Figura 1S, material suplementar), apresentando uma tendência de se manter, praticamente, constante entre o primeiro e o último volume coletado. Esse comportamento é, provavelmente, devido à baixa solubilidade do sulfato de bário $\left(\mathrm{K}_{\mathrm{ps}}=1,1 \times 10^{-10}\right.$ $\left.\mathrm{mol} \mathrm{L}^{-1}\right)$ e ao equilíbrio químico do elemento em solução. No momento em que uma pequena quantidade do bário da solução é removida pela lixiviação, o sulfato de bário libera o elemento para a solução, mantendo-se assim o equilíbrio. ${ }^{33}$

Com base na discussão anterior verificou-se que não há diferença nos teores de bário entre os 8 pontos coletados para cada tratamento. Dessa forma, foi realizada a média dos pontos a fim de se aplicar análise de variância e teste de média para verificar se há diferença significativa (ao nível de 5\%), entre os teores de bário encontrados nos extratos lixiviados, em função das doses e níveis de umidade (Tabela 3 e Figura 1S, material suplementar). Para ambas as condições de umidade, as maiores doses propiciaram as maiores concentrações de bário no efluente lixiviado.

Para a testemunha, verifica-se que as concentrações de bário nos efluentes lixiviados são baixas para ambas as condições de umidade e não houve diferença significativa entre o solo com o teor de umidade a $70 \%$ da capacidade de campo e o solo saturado (Tabela 3). Porém, ao avaliar a maior dose observa-se que houve diferença significativa e que a condição de extrema redução promoveu maiores valores do elemento nos extratos coletados. Esses resultados indicam que há um aumento na solubilização do bário sob condições de saturação e baixo potencial redox (Figura 1), principalmente para a maior dose, corroborando os resultados obtidos no fracionamento geoquímico (Tabela 2). Entretanto, vale ressaltar que no método de fracionamento utilizado nesse experimento, a fração F1 corresponde ao bário nas formas solúvel, trocável e ligada a carbonatos, enquanto que os teores no lixiviado correspondem ao bário, principalmente, nas formas solúvel e trocável. Dessa forma, a diferença entre os teores no lixiviado e da fração F1 pode ser explicada pela associação predominante do bário à fração geoquímica carbonato, em decorrência dos elevados valores de $\mathrm{pH}(7,5)$ observados na condição redutora.

$\mathrm{O}$ valor padrão de potabilidade do elemento bário em águas é e de $0,7 \mathrm{mg} \mathrm{L}^{-1}{ }^{16}$ e ao compará-lo com os valores apresentados nos extratos lixiviados observa-se que as concentrações na testemunha atingiram valores abaixo desse padrão (Tabela 3) e que não houve diferença significativa para os teores de umidade. Na dose que re- presenta as concentrações de um solo contaminado com bário (dose de $300 \mathrm{mg} \mathrm{kg}^{-1}$ ) observou-se aumento nos teores, entretanto não há diferença significativa em relação aos teores de umidade. Na dose de $300 \mathrm{mg} \mathrm{kg}^{-1}$ de $\mathrm{BaSO}_{4}$ as concentrações desse elemento no extrato lixiviado foram de $1,5 \mathrm{mg} \mathrm{L}^{-1}$, sendo que esses valores representam o dobro do valor padrão de potabilidade. Ao simularmos um solo com uma contaminação severa (3000 mg kg-1), observou-se que os valores encontrados no extrato lixiviado também foram superiores aos valores das doses anteriores. Verifica-se que para a condição de saturação as concentrações encontradas foram quase que o dobro das concentrações encontradas no solo oxidado. Ao compararmos esses valores com os valores padrões de potabilidade, verifica-se que a $70 \%$ da capacidade de campo os valores estiveram cerca de 3 vezes acima e na condição de saturação os teores de bário apresentaram-se superiores aproximadamente 6 vezes ao limite de potabilidade da água.

Esses resultados demonstram o aumento significativo na solubilidade do bário na condição de saturação do solo, visto que os maiores teores foram encontrados no solo saturado. Entretanto, vale ressaltar que esse comportamento só ocorreu nas doses mais elevadas, demonstrando o risco de contaminação do lençol freático pelo elemento bário e que esse risco é potencializado em solos sob condições de alagamento.

As médias de bário na fração de maior labilidade, pelo método BCR (fração ácido solúvel - F1), antes e após o ensaio de lixiviação para o solo saturado é apresentada na Figura 2. Com a simulação da precipitação pluviométrica e perda do elemento em decorrência da lixiviação, constatou-se que o bário extraído é, possivelmente, proveniente da fração ácido solúvel, visto que se observou redução

Fração Acido Solúvel

(Saturado)

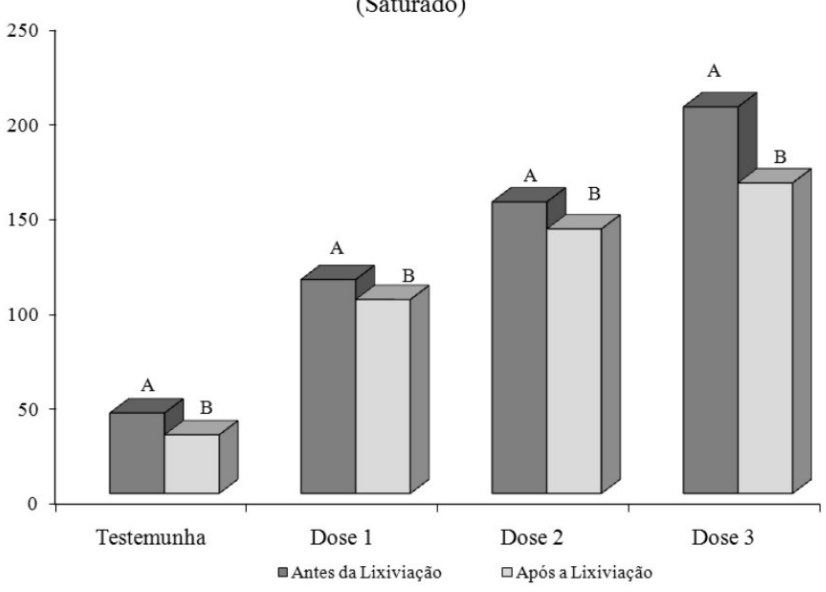

Figura 2. Fração ácido solúvel do elemento bário antes e após a lixiviação, no solo saturado em função das doses de sulfato de bário. Testemunha - sem aplicação de sulfato de bário; dose 1 - $100 \mathrm{mg} \mathrm{kg}^{-1}$; dose 2 - $300 \mathrm{mg} \mathrm{kg}^{-1}$; dose 3 - $3000 \mathrm{mg} \mathrm{kg}^{-1}$

Tabela 3. Médias dos teores* de bário $\left(\mathrm{mg} \mathrm{L}^{-1}\right)$ coletados nos extratos lixiviados em função das diferentes doses e teores de umidade, simulando taxa de precipitação de $200 \mathrm{~mm} \mathrm{dia}^{-1}$

\begin{tabular}{|c|c|c|c|c|c|}
\hline Tratamentos & Testemunha & Dose de 100 & $\begin{array}{l}\text { Dose de } 300 \\
-\mathrm{mg} \mathrm{kg}^{-1}\end{array}$ & Dose de 3000 & $\mathrm{CV}$ \\
\hline $70 \%$ C.C & $0,19 \mathrm{Da}$ & $0,85 \mathrm{Ca}$ & $1,29 \mathrm{Ba}$ & $2,41 \mathrm{Ab}$ & 3,87 \\
\hline Saturado & 0,09 Da & $0,42 \mathrm{Cb}$ & $1,52 \mathrm{Ba}$ & $4,02 \mathrm{Aa}$ & \\
\hline
\end{tabular}

*Médias correspondentes dos 8 pontos coletados. Médias seguidas de mesma letra (minúsculas são comparadas nas colunas e maiúsculas nas linhas) não diferem significativamente pelo teste de Tukey a 5\%. Testemunha - sem aplicação de sulfato de bário. 
significativa das concentrações extraídas desse elemento após a lixiviação. Esses resultados corroboram a discussão do fracionamento geoquímico e teores no lixiviado, confirmando que o bário presente no extrato coletado é proveniente da fração de maior labilidade, sendo o aumento desse elemento potencializado pelas condições de solo em extrema redução.

Em ambientes que apresentam extrema redução, bactérias anaeróbicas aumentam a solubilidade do $\mathrm{BaSO}_{4}$, resultando em maiores concentrações de bário dissolvido. ${ }^{32}$ Crecelius et al., ${ }^{31}$ estudando a solubilidade da baritina em diferentes condições ambientais, também verificaram que em condições de oxidação houve baixa liberação de bário, enquanto que condições de redução resultaram em concentrações mais elevadas de bário em solução. Diversos trabalhos evidenciam que em solos com valores baixos de Eh $(<-220 \mathrm{mV})$ e na presença de $\mathrm{BaSO}_{4}$, bactérias redutoras de sulfato são responsáveis pela solubilização e aumento do bário em solução. ${ }^{10,34,35}$

A Figura 3 apresenta a quantidade de bário removido por cada volume coletado no lixiviado e o total removido em função das doses aplicadas e níveis de umidade. A remoção de bário ocorreu de forma diferenciada, principalmente, em função das doses aplicadas e aumentaram de forma significativa e linear. Verifica-se na testemunha que houve pequena remoção em cada volume coletado, ocasionando baixa quantidade removida $\left(0,3 \mathrm{mg}\right.$ coluna $\left.{ }^{-1}\right)$, evidenciada pela baixa inclinação da reta que representa esse tratamento. Para a dose de $300 \mathrm{mg} \mathrm{kg}^{-1}$ observa-se que houve maior remoção do que nos tratamentos anteriores, porém os valores removidos nas distintas condições de umidade do solo foram bem próximos, sendo de $2,1 \mathrm{mg}$

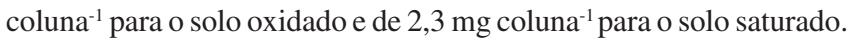
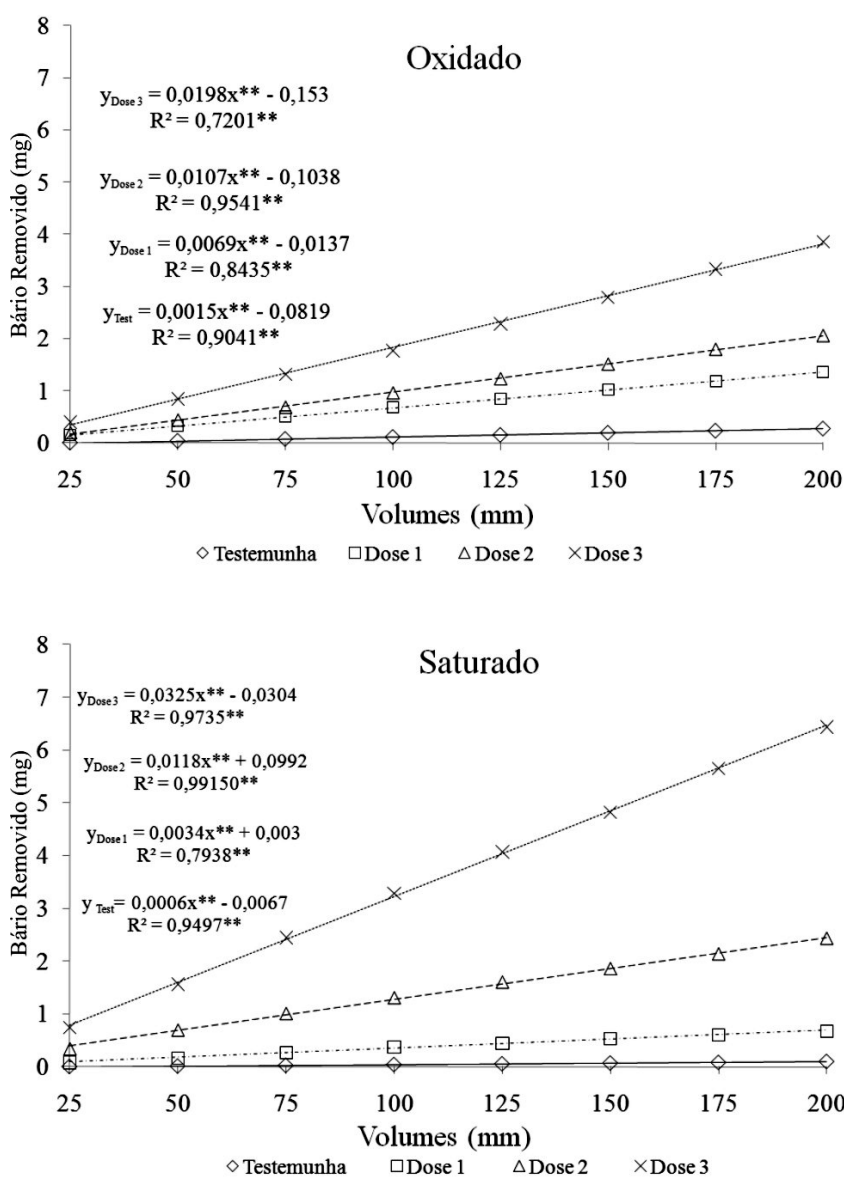

Figura 3. Quantidades de bário ( $\mathrm{mg}$ ) acumulado em função do volume coletado. Testemunha - sem aplicação de sulfato de bário; dose 1 - $100 \mathrm{mg} \mathrm{kg}^{-1}$; dose 2 - $300 \mathrm{mg} \mathrm{kg}^{-1}$; dose $3-3000 \mathrm{mg} \mathrm{kg}^{-1}$
Entretanto, na maior dose para o solo com teor de umidade a $70 \%$ da capacidade de campo, verifica-se que o total de bário removido foi de 3,7 mg coluna ${ }^{-1}$, enquanto que no solo saturado a remoção foi superior, apresentando valores de $6,6 \mathrm{mg}_{\text {coluna }}{ }^{-1}$. Esses resultados evidenciam a influência das condições de redução na maior solubilidade do bário para essa dose.

Levando-se em consideração as condições mais restritivas do experimento e com a finalidade de avaliar qual é a porcentagem de bário removido em relação ao total contido nas colunas, calculou-se o total de bário presente na maior dose. O total de bário extraído nas condições extremas foi de aproximadamente $7 \mathrm{mg}$ coluna ${ }^{-1}$, correspondente a $0,05 \%$ do total da coluna.

\section{CONCLUSÕES}

A condição de redução propiciou o aumento dos teores de bário nas frações de maior labilidade e diminuição na forma mais estável.

Os maiores teores de bário no extrato lixiviado foram encontrados na maior dose e na condição de solo saturado e estiveram acima dos valores padrões de potabilidade, evidenciando o risco de contaminação do lençol freático.

Apenas $0,05 \%$ do total de bário contido na coluna que recebeu a maior dose foram removidos pela lixiviação.

\section{MATERIAL SUPLEMENTAR}

O material suplementar, disponível em http://quimicanova.sbq. org.br, em arquivo pdf e com acesso livre, traz figura que mostra as concentrações de bário dos 8 pontos coletados nos extratos lixiviados, para a testemunha, três doses em função do teor de umidade e padrão para potabilidade (Figura 1S).

\section{REFERÊNCIAS}

1. World Health Organization; Environmental health criteria 107, Geneva. 1990.

2. Fam, M. A.; Dusseault, M. B.; Fooks, J. C.; Journal of Petroleum Science and Engineering 2003, 38, 155.

3. http://www.epa.gov/iris/toxreviews/0010tr.pdf, acessada em Setembro 2010.

4. Pozebon, D.; Lima, E. C.; Maia, S. M.; Fachel, J. M. G.; Fuel 2005, 84, 53.

5. Melton, H. R.; Smith, J. P.; Martin, C. R.; Nedwed, T. J.; Mairs, H. L.; Raught, D. L.; Boletim do Instituto Brasileiro do Petróleo 2000, IBP 44900, 1 .

6. Goncalves, G. K.; Sousa, R. O.; Vahl, L. C.; Bortolon, L.; Rev. Bras. Ciênc. Solo 2008, 32, 5.

7. Ponnamperuma, F. N.; Adv. Agron. 1972, 24, 29.

8. Monnin, C.; Dupre, C. G.; Elderfield, H.; Mottl, M. M.; Geochem. Geophys. Geosyst. 2001, 2, 15.

9. Coscione, A. R.; Berton, R. S.; Sci. Agric. 2009, 66, 59.

10. Baldi, F.; Pepi, M.; Burrini, D.; Kniewald, G.; Scali, D.; Lanciotti, E.; Applied and Environmental Microbiology 1996, 62, 2398.

11. Phillips, E. J. P.; Landa, E. R.; Kraemer, T.; Zielinski, R.; Geomicrobiology 2001, 18, 167.

12. Ulrich, G. A.; Breit, G. N.; Cozzarelli, I. M.; Suflita, J. M.; Environ. Sci. Technol. 2003, 37, 1093.

13. Nogueira, T. A. R.; Demelo, W. J.; Fonseca, I. M.; Marques, M. O.; He, Z.; J. Hazard. Mater. 2010, 181, 1148.

14. Empresa Brasileira de Pesquisa Agropecuária; Manual de métodos de análises de solos, $2^{\mathrm{a}}$ ed., CNPS: Rio de Janeiro, 1997.

15. International Organization for Standardization; Soil quality - Extraction of trace elements soluble in aqua regia, Geneva, 1995. 
16. Brasil, Conselho Nacional do Meio Ambiente; Resolução CONAMA $n^{o}$. 420 , de 28/12/2009. Dispõe sobre critérios e valores de qualidade do solo quanto à presença de substâncias químicas e estabelece diretrizes para o gerenciamento ambiental de áreas contaminadas por essas substâncias em decorrência de atividades antrópicas.

17. Sahuquillo, A.; López-Sánches, J. F.; Rubio, R.; Rauret, G.; Thomas, R. P.; Davidson, C. M.; Ure, A.; Anal. Chim. Acta 1999, 382, 317.

18. Camargo, O. A.; Alleoni, L. R. F.; Casagrande, J. C. Em Micronutrientes e elementos tóxicos na agricultura; Ferreira, M. E.; Cruz, M. C. P.; Raij, B. van.; Abreu, C. A., eds.; POTAFOS: Jaboticabal, 2001, cap. 5.

19. Vepraskas, M. J.; Faulkner, S. P. Em Wetland Soils: Genesis, Hydrology, Landscapes, and Classification; Richardson and Vepraskas, M. J., ed.; LPHS: Boca Raton, 2001, cap. 4.

20. Sousa, R. O.; Bohnen, H.; Meurer, E. J. R.; Bras. Ci. Solo 2002, 26, 343.

21. Lima, E. N.; Mello, J. W. V.; Schaefer, C. E. G. R.; Ker, J. C.; Acta Amazônica 2005, 35, 317.

22. Camargo, F. N. O.; Araujo, G. S.; Zonta, E.; Ciência Rural 1999, 29, 171.

23. Ponnamperuma, F. N.; Soils and Rice, IRRI: Los Baños, 1978.

24. Marin, B.; Valladon, M.; Polve, M.; Monaco, A.; Anal. Chim. Acta 1997, $342,91$.
25. Filgueiras, A. V.; Lavilla, I.; Bendicho, C.; Sci. Total Environ. 2004, 330, 115.

26. Rodriguez, L.; Ruiz, E.; Alonso-Azcarate, J.; Rincon, J.; J. Environ. Management 2009, 90, 1106.

27. Chlopecka, A.; Sci. Total Environ. 1996, 188, 253.

28. Bodek, L.; Lyman, W. J.; Reehi, W. F.; Rosenblatt, D. H.; Environmental Inorganic Chemistry: Properties, Processes, Estimation Methods, Pergamon Press: New York, 1988.

29. Smeda, A.; Zyrnicki, W.; Microchemical 2002, 72, 9.

30. Dang, Z.; Liu, C.; Haigh, M. J.; Environ. Pollut. 2002, 118, 419.

31. Crecelius, E. J.; Trefry, J.; Mckinley, B.; Lasorsa, D.; Trocine, R.; U. S. Dept. of the Interior, Minerals Management Service, Gulf of Mexico OCS Region, New Orleans, LA, OC5 Study MMS 2007-061, 2007.

32. http://environment.alberta.ca/01061.html, acessada em Junho 2011.

33. Binmerdhah, A. B.; Yassin, A. A. M.; Muherei, M. A.; Journal of Petroleum Science and Engineering 2010, 70, 79.

34. Bolze, C. E.; Malone, P.G.; Smith, M.J.; Chem. Geol. 1974, 13, 141.

35. McCready, R. G. L.; Krouse, H. R.; Geomicrobiology 1980, 2, 55. 


\section{MOBILIDADE DE BÁRIO EM SOLO TRATADO COM SULFATO DE BÁRIO SOB CONDIÇÃO DE OXIDAÇÃO E} REDUÇÃO

Marcio Osvaldo Lima Magalhães*, Nelson Moura Brasil do Amaral Sobrinho, Everaldo Zonta, Leilane da Silva Lima e Filipe Soares Diniz de Paiva

Departamento de Solos, Instituto de Agronomia, Universidade Federal Rural do Rio de Janeiro, BR 465, km 7, 23890-000 Seropédica - RJ, Brasil
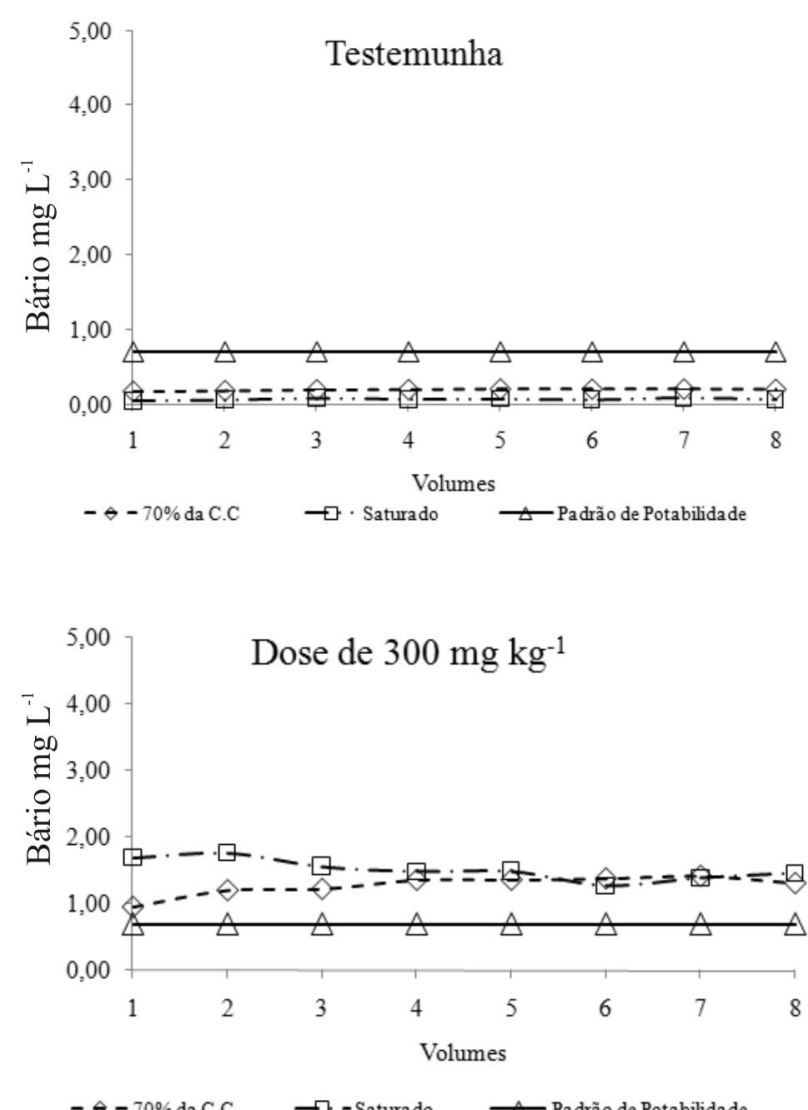

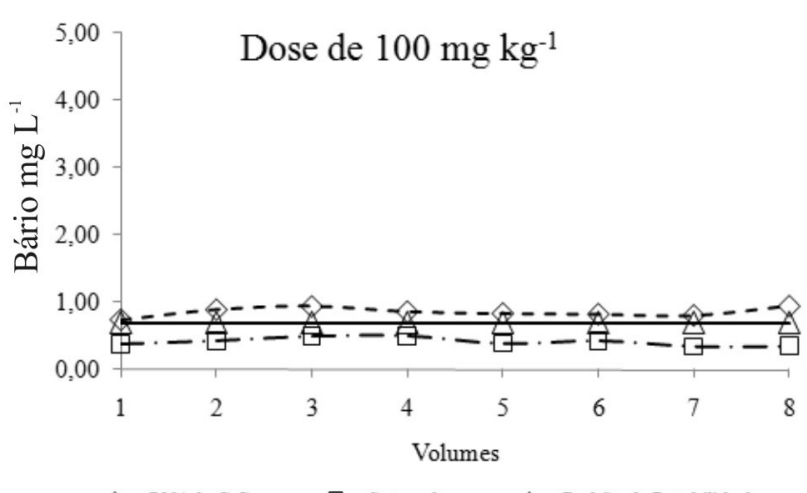

$-\diamond-70 \%$ da C.C $\rightarrow$-Saturado $\quad \longrightarrow$ Padrão de Potabilidade

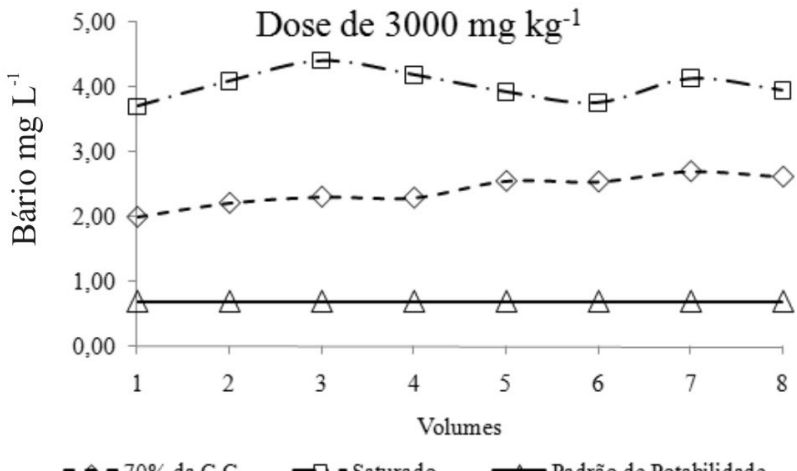

$-\rightarrow 70 \%$ da C.C $\rightarrow$-Saturado $\quad \longleftarrow$ Padrão de Potabilidade

Figura 1S. Concentrações de bário dos 8 pontos coletados nos extratos lixiviados, para a testemunha, três doses em função do teor de umidade e padrão para potabilidade. Padrões para potabilidade (CONAMA, 2009). Testemunha - sem aplicação de sulfato de bário 